\title{
PENGARUH KADAR SILICA FUME TERHADAP KUAT TEKAN PADA HIGH STRENGTH SELF COMPACTING CONCRETE (HSSCC) BENDA UJI SILINDER D 7,5 CM X 15 CM USIA 14 DAN 28 HARI
}

\author{
Wahyu Satrio Wicaksono'), Wibowo'2), Endah Safitri ${ }^{3)}$ \\ 1) Mahasiswa Program Studi Teknik Sipil, Fakultas Teknik, Universitas Sebelas Maret Surakarta \\ 2) 3) Pengajar Program Studi Teknik Sipil, Fakultas Teknik, Universitas Sebelas Maret Surakarta \\ Jalan Ir. Sutami 36A, Surakarta, 57126; Tlp 0271-647069, Email: wsatrio16@gmail.com
}

\begin{abstract}
One of the innovations that can be applied to many construction works is High Strength Self Compacting Concrete (HSSCC). The addition of silica fume which has finer grain when compared with cement aims to increase the compressive strength, while the superplasticizer type BASF-8851 is used to provide good workability. In this study w/b is kept constant at 0,3, superplasticizer levels are 0,8\%, and variations in silica fume levels are $0 \%, 8 \%, 9 \%, 10 \%$ and $11 \%$. This study has two types of concrete tests, i.e. fresh concrete test and hard concrete test. Fresh concrete Fresh concrete were tested by flow table test, l-box test, and v-funnel test. Silica fume with a dossage of $8 \%$ of cements gives the best results which meet all the requirements of SCC parameters. The higher the level of silica fume the lower the concrete workability, it can happen because of the nature of silica fume that absorbs water. Hard concrete tests were performed at 14 days and 28 days. Optimum compressive at 14 days strength results were obtained at 10\% silica fume with strength of $49.39 \mathrm{MPa}$. Meanwhile, the optimum compressive strength occurred at silica fume level of $10.21 \%$. At 28 days, optimum compressive strength results were obtained at $9 \%$ silica fume with strength of 67.65 MPa. Meanwhile, from the results of data analysis showed that the optimum compressive strength occurred at silica fume level of $9.37 \%$.
\end{abstract}

Keyword : Silica fume, self compacting concrete, high strength concrete, $7,5 \mathrm{~cm} \times 15 \mathrm{~cm}$ cylindrical specimen.

\begin{abstract}
Abstrak
Beton mutu tinggi yang mampu memadat mandiri (high strength self compacting concrete-HSSCC) merupakan salah satu inovasi beton yang dapat diaplikasikan pada banyak pekerjaan konstruksi. Penambahan silica fume yang memiliki butiran lebih halus jika dibandingkan dengan semen bertujuan untuk meningkatkan kuat tekan, sedangkan superplasticizer jenis BASF tipe 8851 digunakan untuk memberikan kinerja yang baik pada beton. Nilai w/b pada penelitian kali ini dijaga konstan sebesar 0,3, kadar superplasticizer adalah 0,8\%, dan variasi kadar silica fume sebesar $0 \%, 8 \%, 9 \%, 10 \%$ dan 11\%. Pengujian beton segar dilakukan dengan 3 metode, yaitu flow table test, l-box test, dan $v$ funnel test. Dari hasil pengujian tersebut, silica fume dengan kadar $8 \%$ memberikan hasil terbaik yang mana memenuhi seluruh persyaratan dari masing-masing metode. Semakin tinggi kadar silica fume maka kinerja beton semakin berkurang. Hal ini terjadi karena sifat silica fume yang menyerap air. Pengujian beton keras dilakukan pada umur 14 hari dan 28 hari. Sementara hasil analisis data menunjukkan bahwa kuat tekan optimum terjadi pada kadar silica fume sebesar $10,21 \%$, sedangkan hasil penelitian menunjukkan bahwa kuat tekan optimum pada umur 28 hari terjadi pada penambahan silica fume sebesar 9\% yang memiliki kuat tekan sebesar 67,65 MPa. Sementara dari hasil analisis data menunjukkan bahwa kuat tekan optimum terjadi pada kadar silica fume sebesar 9,37\%.
\end{abstract}

Kata Kunci : Silica fume, beton memadat mandiri, beton mutu tinggi, benda uji silinder d 7,5 cm x $15 \mathrm{~cm}$.

\section{PENDAHULUAN}

Kriteria beton mutu tinggi telah berubah sejalan dengan perkembangan teknologi beton yang demikian pesatnya. Pada tahun 1950, beton dikategorikan memiliki mutu tinggi jika nilai kuat tekannya mencapai $30 \mathrm{MPa}$, sedangkan tahun 1960-1970 kriteria nilai kuat tekan beton mutu tinggi naik menjadi $40 \mathrm{MPa}$ (Mulyono, 2004).

Banjir di Kelurahan Sumber dianalisis dengan cara melakukan penelusuran banjir pada Kali Gajah Putih. Penelusuran banjir akan menghasilkan hidrograf pada suatu titik dengan titik lainnya di sepanjang aliran sungai. Penelusuran banjir sangat penting dalam upaya pengendalian banjir. Pemerintah dan masyarakat dapat melakukan evakuasi dini sehingga memperkecil kemungkinan kerugian jiwa, harta dan benda. 
Menurut SNI 03-6468-2000 beton mutu tinggi didefinisikan sebagai beton yang memiliki nilai kuat tekan minimum sebesar 41,4 $\mathrm{MPa}$.

Beton memadat mandiri (self compacting concrete, SCC) merupakan beton yang mampu mengalir karena beratnya sendiri yang dapat dicetak pada bekisting yang memungkinkannya mengalir sendiri mengikuti arah gravitasi dengan tingkat penggunaan alat pemadat yang sangat sedikit atau bahkan tidak dipadatkan sama sekali. (Ludwing et al, 2001).

Okamura and Ozawa (1995), merekomendasikan metode dengan mix design sederhana berdasarkan pada bahanbahan yang tersedia di pabrik beton ready-mix dengan spesifikasi bahan volume agregat kasar kurang dari $50 \%$ dari volume total, volume agregat halus $40 \%$ dari volume mortar, faktor air semen (w/c) yang ditetapkan rendah, dan dosis superplasticizer dan faktor w/b ditentukan setelahnya untuk memastikan kepadatannya. Berdasarkan Tabel 1, EFNARC (2005) merekomendasikan range komposisi beton SCC untuk permeter kubiknya seperti di bawah ini.

Tabel 1. Mix Design yang Disarankan oleh EFNARC (2005)

\begin{tabular}{ccc} 
Bahan Material & Range dalam massa $\mathbf{( k g / \mathbf { m } ^ { 3 } )}$ & Range dalam volume $\left(\mathbf{l i t e r} / \mathbf{m}^{3}\right)$ \\
\hline Powder & $380-600$ & $300-380$ \\
\hline Pasta & $150-210$ & $150-210$ \\
\hline Air & $750-1000$ & $270-360$ \\
\hline Agregat Kasar & $48 \%-55 \%$ dari total berat agregat \\
\hline Agregat Halus & $0,85-1,10$ \\
\hline Rasio w/b dari volume & & 0,05 \\
\hline
\end{tabular}

Silica fume merupakan mineral admixture yang berupa material pozzolan halus yang memiliki komposisi silika lebih banyak dari pozzolan halus lainnya, yang berasal dari tanur tinggi atau sisa produksi silikon dan alloy besi silikon dengan ciri fisik berupa warna abu-abu dengan diameter sekitar 0,1 - 0,2 $\mu \mathrm{m}$. Untuk sifat kimia, persentase SiO2 silica fume lebih dominan dari senyawa-senyawa lain, dengan persentase diatas $90 \%$ dan sisanya terdiri dari senyawa-senyawa lain.

Dengan ukuran partikel yang sangat halus, silica fume memiliki kemampuan untuk mengisi ruang kosong pada beton sehingga campuran beton mengalami proses penjenuhan (lebih rapat) yang dapat meningkatkan kuat tekan dan impermeabilitasnya. Pengaruh lainnya yaitu sebagai bahan pozolan, dimana $\mathrm{SiO}_{2}$ bereaksi dengan $\mathrm{Ca}(\mathrm{OH})_{2}$ yang merupakan bahan sisa dari hasil hidrasi semen yang kemudian menghasilkan kalsium silikat hidrat (CSH) sebagaimana yang dihasilkan hidrasi semen yang memberikan kekuatan pada beton kerasnya. Reaksi tersebut tersebar merata sehingga menambah kekuatan lekatan antara agregat dan pasta semen.

\section{METODE}

\section{Rancang Campur (Mix Design)}

Komposisi jumlah agregat yang digunakan tiap $1 \mathrm{~m}^{3}$ beton dapat dilihat pada Tabel 2. di bawah ini.

Tabel 2. Rancang Campur Bscc - SF per $1 \mathrm{~m}^{3}$

\begin{tabular}{cccccccc}
\hline Kode. & $\begin{array}{c}\text { Kadar } \\
\text { Silica } \\
\text { Fume }\end{array}$ & $\begin{array}{c}\text { Ag. Kasar } \\
\left(\mathbf{K g} / \mathbf{m}^{3}\right)\end{array}$ & $\begin{array}{c}\text { Ag. } \\
\left.\mathbf{H g} / \mathbf{m}^{3}\right)\end{array}$ & $\begin{array}{c}\text { Semen } \\
\left(\mathbf{K g} / \mathbf{m}^{3}\right)\end{array}$ & $\begin{array}{c}\text { Silica } \\
\text { Fume } \\
\left(\mathbf{K g} / \mathbf{m}^{3}\right)\end{array}$ & $\begin{array}{c}\text { Air } \\
\left(\mathbf{l t} / \mathbf{m}^{3}\right)\end{array}$ & $\begin{array}{c}\text { SP } \\
\left(\mathbf{l t} / \mathbf{m}^{3}\right)\end{array}$ \\
\hline $\begin{array}{c}\text { Bscc-SF } \\
\mathbf{0} \%\end{array}$ & $0 \%$ & 784,76 & 703,52 & 696,03 & 0 & 187,93 & 11,11 \\
\hline $\begin{array}{c}\text { Bscc-SF } \\
\mathbf{8} \%\end{array}$ & $8 \%$ & 784,76 & 703,52 & 629,91 & 54,77 & 184,86 & 10,93 \\
\hline $\begin{array}{c}\text { Bscc-SF } \\
\mathbf{9 \%}\end{array}$ & $9 \%$ & 784,76 & 703,52 & 621,79 & 61,50 & 184,49 & 10,91 \\
\hline $\begin{array}{c}\text { Bscc-SF } \\
\mathbf{1 0} \%\end{array}$ & $10 \%$ & 784,76 & 703,52 & 613,71 & 68,19 & 184,11 & 10,88 \\
\hline $\begin{array}{c}\text { Bscc-SF } \\
\mathbf{1 1 \%}\end{array}$ & $11 \%$ & 784,76 & 703,52 & 605,66 & 74,86 & 183,74 & 10,86 \\
\hline
\end{tabular}




\section{Pengujian Beton Segar}

Pengujian beton segar dilakukan terhadap parameter dari SCC yaitu fillingability, passingability, dan segregation resistance. Adapun pengujian-pengujian tersebut berupa Flow Table Test, L-Box Test, dan V-Funnel Test.

\section{Pengujian Beton Keras}

Pengujian yang dilakukan terhadap beton keras adalah pengujian kuat tekan beton dengan menggunakan Compressive Testing Machine (CTM) pada umur beton 14 hari dan 28 hari.

\section{HASIL DAN PEMBAHASAN}

\section{Pengujian Beton Segar}

Hasil pengujian beton segar untuk masing-masing kadar silica fume dapat dilihat pada Tabel 3. dibawah ini.

Tabel 3. Hasil Pengujian Beton Segar

\begin{tabular}{|c|c|c|c|c|c|c|c|c|c|c|c|c|}
\hline \multirow[b]{2}{*}{ Kode } & \multicolumn{4}{|c|}{ Flow Table Test } & \multicolumn{4}{|c|}{ L-Box Test } & \multicolumn{4}{|c|}{ V-Funnel Test } \\
\hline & $\begin{array}{l}\mathrm{d}_{\text {rerata }} \\
(\mathrm{mm})\end{array}$ & $\begin{array}{c}\text { Syarat } \\
(\mathrm{mm})\end{array}$ & $\begin{array}{l}\mathrm{T}_{500} \\
(\mathrm{~s})\end{array}$ & $\begin{array}{c}\text { Syarat } \\
\text { (s) }\end{array}$ & $\mathrm{h}_{2} / \mathrm{h}_{1}$ & $\begin{array}{l}\text { Syarat } \\
\mathrm{h}_{2} / \mathrm{h}_{1}\end{array}$ & $\begin{array}{c}\mathrm{T}_{200} \\
(\mathrm{~s})\end{array}$ & $\begin{array}{c}\mathrm{T}_{400} \\
(\mathrm{~s})\end{array}$ & $\begin{array}{c}\text { Waktu } \\
\text { Aliran } \\
\text { Awal / } \\
\mathrm{T}_{\text {awal }} \\
\text { (s) }\end{array}$ & $\begin{array}{c}\text { Syarat } \\
\mathrm{T}_{\text {awal }} \\
(\mathrm{s})\end{array}$ & $\begin{array}{c}\text { Waktu } \\
\text { Aliran } 5 \\
\text { menit } \\
/ \mathrm{T}_{5 \min } \\
(\mathrm{s})\end{array}$ & $\begin{array}{c}\text { Syarat } \\
\mathrm{T}_{5 \min } \\
(\mathrm{s})\end{array}$ \\
\hline $\begin{array}{c}\text { Bscc } \\
- \text { SF } \\
0 \%\end{array}$ & 665 & $\begin{array}{c}650 \\
- \\
800\end{array}$ & 3,1 & $2-5$ & 1,00 & $\begin{array}{c}0,8 \\
- \\
1,0\end{array}$ & 1,0 & 2,7 & 8,3 & $8-12$ & 12,2 & +3 \\
\hline $\begin{array}{c}\text { Bscc } \\
- \text { SF } \\
8 \%\end{array}$ & 705 & $\begin{array}{c}650 \\
- \\
800\end{array}$ & 2,1 & $2-5$ & 0,88 & $\begin{array}{c}0,8 \\
- \\
1,0\end{array}$ & 1,2 & 2,0 & 9,5 & $8-12$ & 11,9 & +3 \\
\hline $\begin{array}{c}\text { Bscc } \\
- \text { SF } \\
9 \%\end{array}$ & 680 & $\begin{array}{c}650 \\
- \\
800\end{array}$ & 3,6 & $2-5$ & 0,82 & $\begin{array}{c}0,8 \\
- \\
1,0\end{array}$ & 1,6 & 4,5 & 10,2 & $8-12$ & 17,2 & +3 \\
\hline $\begin{array}{l}\text { Bscc } \\
- \text { SF } \\
10 \%\end{array}$ & 660 & $\begin{array}{c}650 \\
- \\
800\end{array}$ & 4,5 & $2-5$ & 0,63 & $\begin{array}{c}0,8 \\
- \\
1,0\end{array}$ & 2,3 & 6,9 & 16,3 & $8-12$ & 24,4 & +3 \\
\hline $\begin{array}{c}\text { Bscc } \\
- \text { SF } \\
11 \%\end{array}$ & 655 & $\begin{array}{c}650 \\
- \\
800\end{array}$ & 6,2 & $2-5$ & 0,55 & $\begin{array}{c}0,8 \\
- \\
1,0\end{array}$ & 2,7 & 7,4 & 19,4 & $8-12$ & 26,0 & +3 \\
\hline
\end{tabular}

Flow Table Test

Hasil pengujian Flow Table dapat dilihat pada Gambar 1. Dan Gambar 2. berikut.

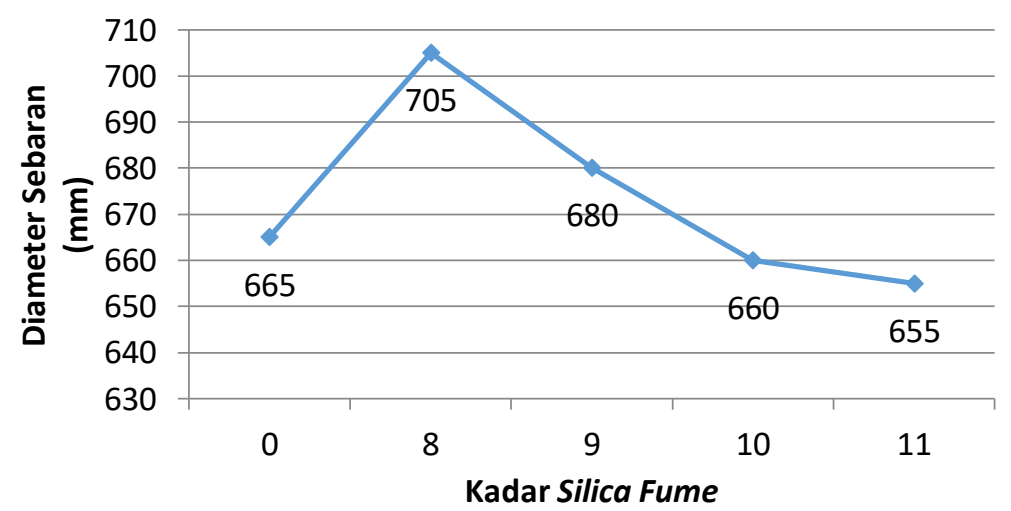

(\%) 


\section{Gambar 1. Grafik Diameter Sebaran Flow Table Test dengan Kadar Silica Fume}

Berdasarkan Gambar 1. beton dengan variasi kadar silica fume 8\% memiliki diameter tertinggi jika dibandingkan dengan variasi kadar lainnya yaitu sebesar $665 \mathrm{~mm}$. Nilai sebaran berangsur menurun di kadar $9 \%$, 10\%, dan $11 \%$. Penurunan nilai sebaran ini disebabkan oleh kekentalan (viskositas) pada adukan beton yang makin meningkat. Apabila dilihat dari nilai sebarannya, silica fume berdampak baik pada adukan beton karena membuat kekentalan (viskositas) adukan beton menjadi lebih kecil daripada beton normal tanpa penambahan silica fume.

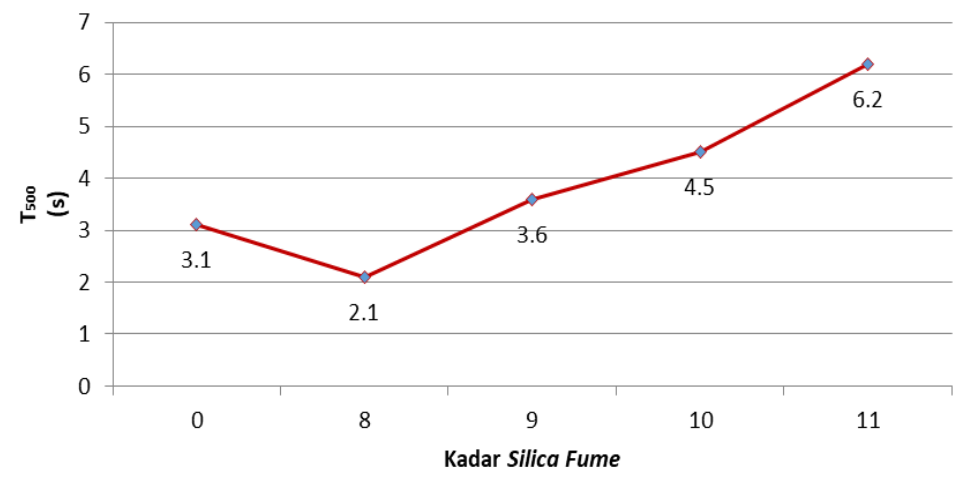

(\%)

Gambar 2. Grafik $T_{500}$ pada Flow Table Test dengan Kadar Silica Fume

Berdasarkan Gambar 2, dapat disimpulkan bahwa silica fume banyak menyerap air, hal ini sejalan dengan seiring bertambahnya kadar silica fume pada adukan beton, semakin banyak kadar silica fume yang ditambahkan, semakin banyak juga air yang terserap. Hal ini sesuai dengan pernyataan Ouchi et al (1998) yang mengatakan bahwa fungsi filler selain mengisi ruang kosong juga meningkatkan kekentalan dari campuran beton agar campuran terhindar dari segregasi. Oleh karena itu, semakin banyak kadar silica fume yang ditambahkan, maka semakin lama pula waktu yang diperlukan beton untuk mencapai $\mathrm{t}_{500}$. Hal ini dikarenakan bertambahnya kadar silica fume menambah kekentalan pada beton. Hal ini sejalan dengan penelitian yang dilakukan oleh Tangtermsirikul dan Khayat (2000) bahwa jika kekentalan beton semakin tinggi maka waktu pengalirannya juga akan semakin lama.

L-Box Test

Hasil pengujian L-Box dapat dilihat pada Gambar 3. Dan Gambar 4. berikut.

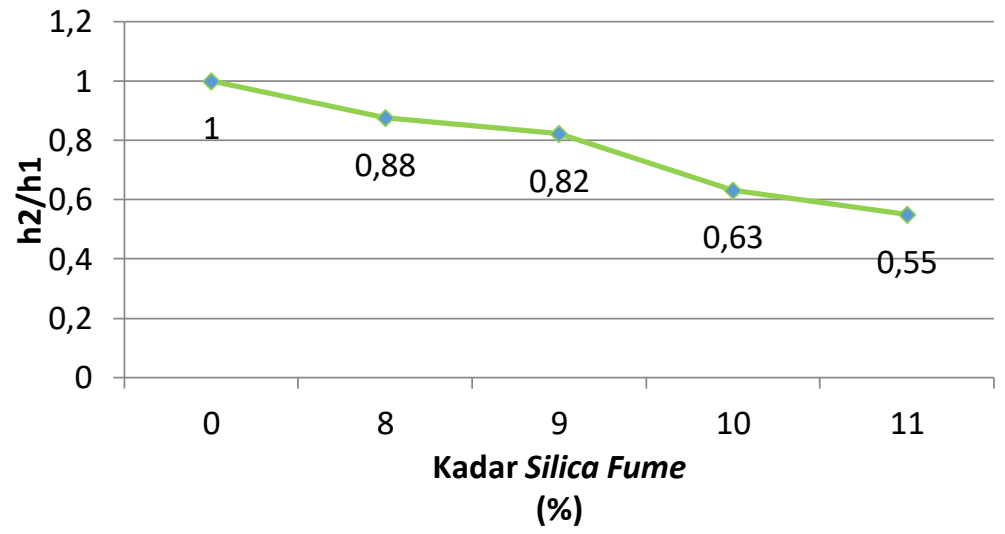

Gambar 3. Grafik $\mathrm{h}_{2} / \mathrm{h}_{1}$ pada L-Box Test dengan Kadar Silica Fume

Berdasarkan Gambar 3, silica fume dengan variasi kadar 8\% memiliki perbandingan $\mathrm{h} 2 / \mathrm{h} 1$ yang paling baik dibandingkan dengan variasi kadar lainnya, yaitu sebesar 0,88 . Hal ini menunjukkan bahwa beton SCC dengan varisasi kadar $8 \%$ memiliki kemampuan mengisi ruang dan perataan yang paling baik daripada variasi kadar lainnya, sedangkan untuk variasi kadar silica fume sebesar $9 \%$ mengalami penurunan nilai perbandingan $\mathrm{h} 2 / \mathrm{h} 1$ namun masih memenuhi syarat EFNARC (2002) dengan nilai 0,82. Berbeda dengan variasi kadar 8\% dan 9\%, 
variasi kadar 10\% dan 11\% tidak memenuhi syarat EFNARC (2002) karena nilai perbandingan $\mathrm{h} 2 / \mathrm{h} 1$ sebesar 0,63 dan 0,55. Pada pengujian ini dapat disimpulkan bahwa semakin tinggi kadar silica fume yang ditambahkan pada beton, maka semakin tinggi nilai kekentalan pada beton segar tersebut.

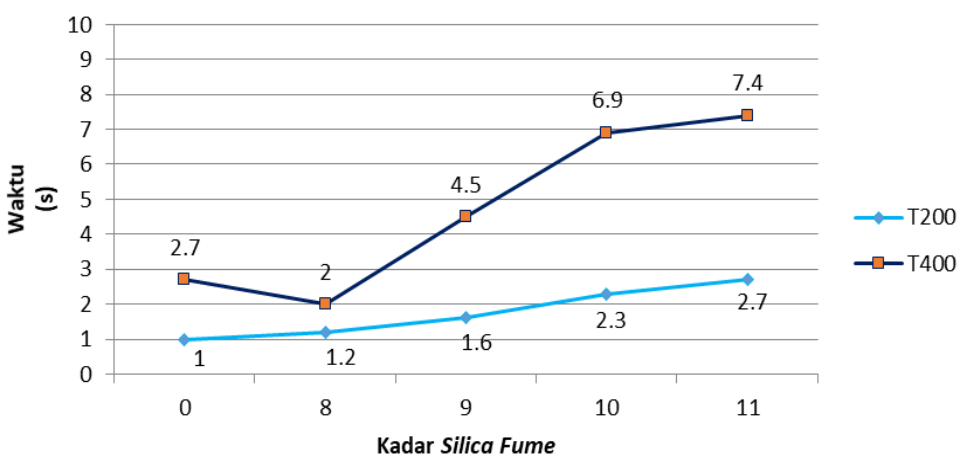

(\%)

Gambar 4. Grafik $T_{200} \mathrm{~cm}$ dan $\mathrm{T}_{400} \mathrm{~cm}$ pada L-Box Test dengan Kadar Silica Fume

Berdasarkan Gambar 4 dapat disimpulkan bahwa campuran beton memerlukan waktu yang bertambah lama untuk mencapai panjang sebaran $200 \mathrm{~mm}\left(\mathrm{t}_{200}\right)$ dan $400 \mathrm{~mm}\left(\mathrm{t}_{400}\right)$ berbanding lurus dengan semakin banyaknya kadar silica fume yang ditambahkan pada adukan beton. Hal ini disebabkan akibat kekentalan beton yang semakin bertambah seiring dengan besarnya kadar silica fume yang ditambahkan pada adukan beton. Hal ini sesuai dengan pernyataan Tangtermsirikul and Khayat (2000) yang menyebutkan bahwa kekentalan beton yang tinggi akan memperlambat waktu alir karena beton membutuhkan energi yang lebih besar pula untuk melewati tulangan namun sebaliknya jika kekentalan beton rendah maka akan mengakibatkan aggregate blocking.

\section{$V$-Funnel Test}

Hasil pengujian $V$-Funnel dapat dilihat pada Gambar 5. berikut.

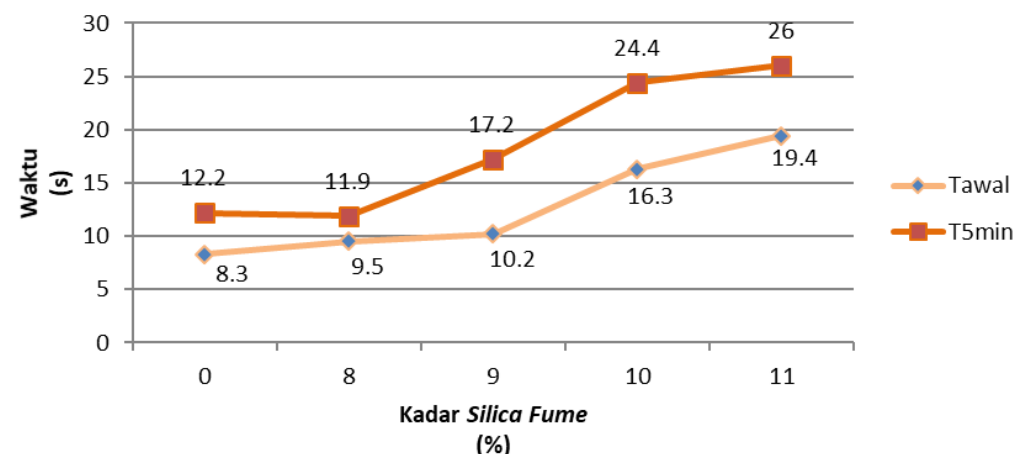

Gambar 5. Grafik Waktu Aliran pada V-funnel Test dengan Kadar Silica Fume

Berdasarkan Gambar 5, kadar silica fume 8\% merupakan satu-satunya kadar yang memenuhi syarat EFNARC (2002) untuk pengujian v-funnel dengan waktu yang diperlukan dibawah 12 detik, yaitu selama 9,5 detik dengan $\mathrm{T}_{5 \min }$ selama 11,9 detik. Kadar 9\% memenuhi syarat $v$-funnel untuk $\mathrm{T}_{0 \min }$ namun tidak memenuhi syarat $\mathrm{T}_{5 \min }$. Dari 
gambar diatas dapat diketahui bahwa semakin tinggi kadar silica fume maka waktu yang dibutuhkan campuran untuk mengalir semakin besar dikarenakan campuran beton memiliki kekentalan yang tinggi. Dengan tidak terpenuhinya syarat waktu pengaliran pada $\mathrm{T}_{5 \min }$ yaitu sebesar +3 detik dari waktu pengaliran awal maka beton dengan kadar silica fume $9 \%, 10 \%$ dan $11 \%$ mengindikasikan terjadinya segregasi.

\section{Pengujian Beton Keras}

Hasil pengujian kuat tekan beton pada silinder berukuran 7,5x15 cm dengan umur 14 hari dan 28 hari selengkapnya disajikan dalam Tabel 4, sedangkan Gambar 6 menunjukkan perbandingan kuat tekan umur 14 dan 28 hari.

Tabel 4. Hasil Kuat Tekan Beton Umur 14 dan 28 Hari

\begin{tabular}{ccc}
\hline Kode & $\begin{array}{c}\text { Kuat Tekan 14 Hari } \\
\text { (MPa) }\end{array}$ & $\begin{array}{c}\text { Kuat Tekan 28 Hari } \\
\text { (MPa) }\end{array}$ \\
\hline Bscc-SF 0\% & 36,58 & 43,02 \\
\hline Bscc-SF 8\% & 43,95 & 56,68 \\
\hline Bscc-SF 9\% & 45,67 & 67,65 \\
\hline Bscc-SF 10\% & 49,39 & 63,41 \\
\hline Bscc-SF 11\% & 47,25 & 53,90 \\
\hline
\end{tabular}

Dapat dilihat pada Tabel 4 bahwa dengan adanya substitusi silica fume menambah kekuatan tekan beton. Hal ini terjadi karena silica fume memiliki peran ganda pada campuran beton yaitu sebagai filler dan pozzolan. Silica fume mampu berperan sebagai filler yang mengisi ruang kosong diantara agregat dan pasta semen. Dengan berkurangnya ukuran pori dalam beton, maka kekuatan beton akan semakin meningkat.

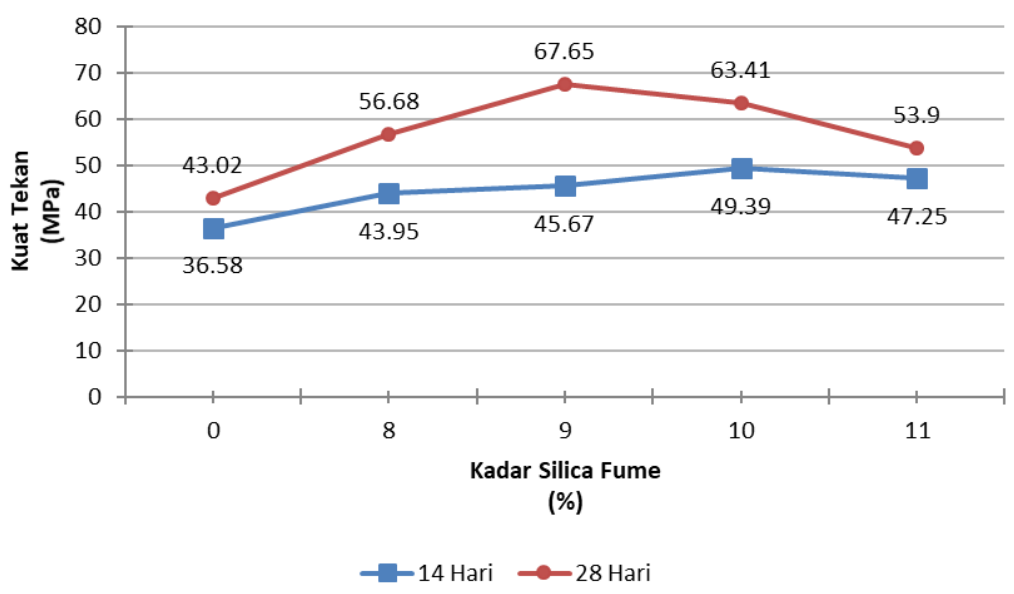

Gambar 6. Grafik Kuat Tekan Beton D 7,5 cm x $15 \mathrm{~cm}$ dengan Kadar Silica Fume

Berdasarkan Gambar 6. kuat tekan beton yang tidak disubstitusikan dengan silica fume (Bscc SF - 0\%) telah memenuhi persyaratan beton mutu tinggi pada umur 28 hari yang mana memiliki kuat tekan sebesar 43,02 MPa. Menurut SNI 03-6468-2000 beton mutu tinggi adalah beton yang memiliki kuat tekan minimum 41,4 MPa. Silica fume meningkatkan kuat tekan beton seiring bertambahnya waktu. Namun, pada kadar tertentu kuat tekan beton dengan silica fume akan menurun dikarenakan sifat silica fume yang menyerap air sehingga menyebabkan kandungan air didalam beton berkurang dan berdampak pada nilai w/b yang menjadi kecil. Nilai w/b yang kecil tidak selalu meningkatkan kuat tekan beton, akan tetapi pada suatu nilai $\mathrm{w} / \mathrm{b}$ tertentu akan membuat kuat tekannya menurun.

Untuk mengetahui nilai optimum kuat tekan optimum dari kadar silica fume yang digunakan maka disajjikan Gambar 7. sebagai berikut. 


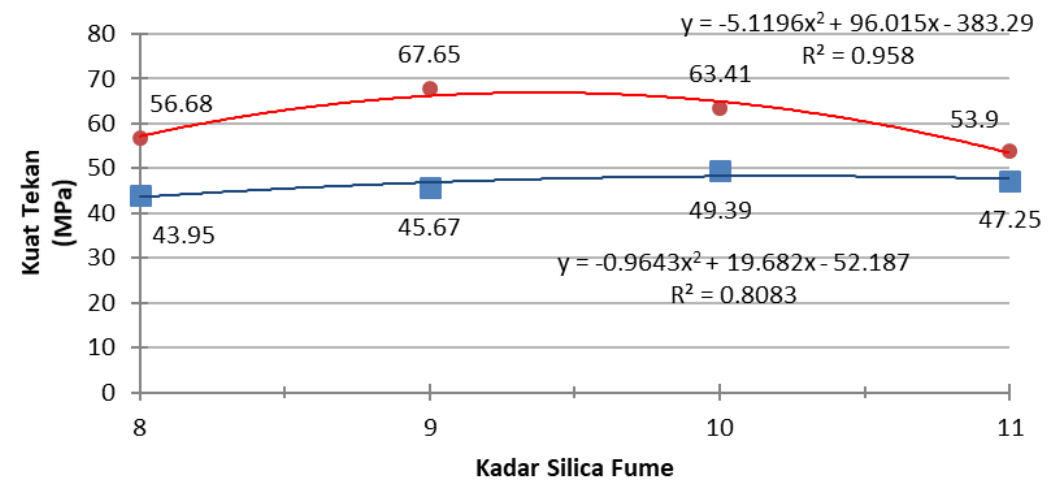

(\%)

14 Hari - Poly. (28 Hari)

Gambar 7. Grafik Hubungan Kuat Tekan Beton D 7,5 cm x 15 cm dengan Kadar Silica Fume

Berdasarkan Gambar 7. diperoleh persamaan kuadratik untuk kuat tekan beton pada umur 14 hari dan 28 hari. Dari persamaan-persamaan kuadratik ini dapat diperoleh persentasi kadar silica fume yang menghasilkan kuat tekan optimum. Persamaan kuadratik untuk kuat tekan umur 14 hari adalah y $=-0,9643 x^{2}+19,682 x-52,187$, sehingga diperoleh nilai kuat tekan optimum terjadi pada kadar silica fume sebesar 10,21\%. Untuk kuat tekan 28 hari, persamaan kuadratiknya adalah $y=-5.1196 x^{2}+96.015 x-383.29$ sehingga nilai kuat tekan optimum berada pada kadar silica fume sebesar 9,37\%.

\section{KESIMPULAN}

Dari hasil pengujian, analisis data, dan pembahasan pada high strength self compacting concrete (HSSCC) benda uji silinder d 7,5 cm x $15 \mathrm{~cm}$ usia 14 dan 28 hari, maka dapat ditarik beberapa kesimpulan yaitu:

a) Berdasarkan hasil pengujian SCC pada beton segar, penggantian semen dengan kadar silca fume sebesar 8\% mampu memenuhi seluruh parameter SCC (fillingability, passingability, dan segregation resistance),

b) Dengan adanya penambahan silica fume pada High Strength Self Compacting Concrete (HSSCC) semakin menambah nilai kuat tekan beton silinder d 7,5 $\mathrm{cm}$ x $15 \mathrm{~cm}$ baik di usia 14 , maupun usia 28 hari,

c) Kuat tekan beton optimum d 7,5 cm x $15 \mathrm{~cm}$ umur 14 hari terjadi pada kadar silica fume sebesar 10,21\% sedangkan pada umur 28 hari terjadi pada kadar silica fume sebesar 9,37\%,

d) Persentase kadar silica fume yang digunakan untuk memenuhi parameter beton mutu tinggi dan beton memadat mandiri pada beton silinder dengan d $7,5 \mathrm{~cm} \times 15 \mathrm{~cm}$ umur pengujian 14 dan 28 hari adalah sebesar $8 \%$ dari total berat semen yang digunakan.

\section{REFERENSI}

Badan Standarisasi Nasional. (2000). Tata Cara Perencanaan Campuran Beton Berkekuatan Tinggi dengan Semen Portland dan Abu Terbang (SNI 03-6468-2000). Jakarta Pusat: Badan Standarisasi Nasional.

EFNARC. (2002). Specification and Guidelines for Self-Compacting Concrete.

EFNARC. (2005). The European Guidelines for Self-Compacting Concrete Specification, Production and Use.

Mulyono, T. (2004). Teknologi Beton. Yogyakarta: Andi Offset.

Okamura, H., and Ozawa, K. (1995). Self-Compactable High Performance Concrete. American Concrete Institute, Detroit.

Ouchi, M., Hibino, M., Ozawa, K and Okamura, H. (1998). A rational mix-design method for mortar in selfcompacting concrete, Proceeding of the 6th East Asia-Pacific Conference on Structural Engineering and Construction, Taipei, ROC, Vol. 2, pp. 1307-1312.

Supartono, FX. (1998). Beton Berkinerja Tinggi dan Keterkaitannya dengan Pembangunan Nasional Memasuki Abad 21. Seminar Material Konstruksi di Jurusan Sipil FTUI, Jakarta, 24 Maret 1998.

Tangtermsirikul, S and Khayat, K. (2000). "Part III: Fresh concrete properties", in: A. Skarendahl, O. Petersson (Eds.), Self-Compacting Concrete, State-of-the-Art Report of RILEM Technical Committee, 17-22. 
